\title{
When acid suppression is not enough: Endoscopy and GERD
}

\author{
Alan BR Thomson MD PhD FRCPC FRCP FACG
}

A lthough the relationship between the percentage of intragastric $\mathrm{pH}$ values equal or greater than $4(\% \mathrm{pH} \geq 4)$ and the healing rates for erosive esophagitis is linear, the slope of the line is small (1). Clinically, this means that a relatively large change in intragastric $\mathrm{pH}$ is needed to achieve a relatively small improvement in healing rates. With esomeprazole $40 \mathrm{mg} /$ day resulting in healing rates of 93\% in eight weeks, and maintenance of healing in $94 \%$ of sufferers of erosive esophagitis followed for six months, it is clear that any enhancement in healing rates would require even further and extensive increases in the number of hours per day that $\mathrm{pH}$ values equal or exceed 4 . Although most patients who are taking proton pump inhibitors (PPIs) are also relieved of their troublesome symptoms from gastroesophageal reflux disease (GERD), symptom relapse is common. Once medical therapy is stopped, erosive esophagitis may recur, and many people become dependent on lifelong therapy. For such individuals who require long term continuous or intermittent PPI therapy, the only other options are endotherapy or laparoscopic fundoplication. Of course, not all patients welcome a surgical approach because of the associated morbidity and postoperative conditions. For them, a nonsurgical means of controlling GERD would be welcomed. While laparoscopic or open surgical operations such as Nissen fundoplication for reflux are effective in highly experienced hands, surgery may result in dysphagia, gas-bloat syndrome, perforation or bleeding. Some patients have severe medical conditions such that a general anesthetic would be ill advised. Unfortunately, a patient will (rarely) succumb from the surgery.

An endoscopic antireflux procedure may be attractive for several reasons. First, in most countries with national health insurance plans, surgical procedures are generally covered, while medications are not. Endoscopic procedures may reduce costs, shorten waiting periods and result in shorter postoperative recovery time and discomfort, with fewer complications and a reduced need for later reinstitution of medical therapy. Four forms of endotherapy are currently under investigation for the treatment of GERD: the endoscopic full-thickness plication system (2); Endocinch (Bard, USA) (3); endoscopic injection of the polymer Enteryx (Enteric Medical Technologies, USA); and the Stretta procedure (Curon Medical, USA) for radiofrequency (RF) delivery to the muscle of the gastroesophageal junction. While these endotherapeutic procedures are not yet widely available in Canada, their use is being widely

Division of Gastroenterology, Department of Medicine, University of Alberta, Edmonton, Alberta

Correspondence: Dr Alan BR Thomson, Department of Medicine, University of Alberta, 519 Newton Research Building, Edmonton, Alberta

T6G 2C2. Telephone 780-407-6490, fax 780-407-7964, e-mail alan.Thomson@ualberta.ca

Received for publication November 13, 2001. Accepted February 8, 2002 
studied, and it will likely only be a short time until the use of at least one of these endotherapies for GERD becomes more widely available and acceptable.

\section{ENDOCINCH}

Endocinch received approval from the United States Food and Drug Administration in March 2000, and is now marketed commercially in that country. A sewing device controls the depth and length of the stitch, as well as a knot tying process, correctly positioned through an endoscope. This endoscopic gastroplasty device has been mainly used as a minimally invasive surgical procedure to treat GERD without laparotomy or laparoscopy (4). It has also been used to close esophageal or gastric perforations, to attach $\mathrm{pH}$ radiotelemetry capsules to the upper gastrointestinal tract, or to attach feeding tubes to the stomach wall. Patients are selected for the treatment of GERD if they have no Barrett's epithelium and if any associated hiatal hernia is less than $2 \mathrm{~cm}$ in diameter. Stitches may be placed below the cardioesophageal junction in a linear or circumferential configuration. In a multicentre American study (5), 64 patients were treated with the use of Endocinch. A three-month follow-up showed significant $(\mathrm{P}<0.0001)$ improvements in heartburn scores (62.5 to 16.6), heartburn severity (22.8 to 9.2 ) and regurgitation (1.8 to 0.6). In a second study involving 107 patients with GERD, treatment with Endocinch resulted in an improvement in symptoms, with a change in the median DeMeester score from 5 to 1 $(\mathrm{P}<0.05)(3)$. There was also an increase in the median length of the lower esophageal sphincter (LES) from 2 to $3 \mathrm{~cm}(\mathrm{P}<0.05)$, an increase in the pressure of the LES from 5 to $8 \mathrm{mmHg}(\mathrm{P}<0.05)$ and a decrease in the median $\% \mathrm{pH} \geq 4$ from 8.4 to $2.7(\mathrm{P}<0.05)$. Clearly, long term studies and guidelines for patient selection are needed to ensure that these initial promising results are sustained, and that, over time, patients do not need to be retreated with PPIs.

\section{THE STRETTA PROCEDURE}

The Stretta system is available for use in the United States, and is marketed by Curon Medical Inc, Sunnyvale, California. Endoscopy is performed first, then the distance from the incisors to the squamocolumnar junction ( $z$-line) is measured and the endoscope is removed. The Stretta catheter is comprised of a bougie tip, a balloon-basket assembly and four electrode delivery sheaths positioned radially around the balloon. These electrode delivery sheaths are passed transorally and positioned up to $1 \mathrm{~cm}$ above the $z$-line. The balloon is inflated and four nickeltitanium needle electrodes (22 gauge, $5.5 \mathrm{~mm}$ length) are inserted into the muscle of the gastrointestinal junction (GEJ). RF energy is delivered to each electrode while the mucosa is cooled with irrigation by using a temperaturecontrolled RF generator system. Additional lesion sets are created in the region from $1 \mathrm{~cm}$ above to $2 \mathrm{~cm}$ below the $z$ line, by rotating the catheter $45^{\circ}$ and varying its linear position. A total of 15 to 25 lesion sets are created in most patients; the exact number is determined by the individual patient's anatomy. Patients then undergo endoscopy immediately after delivery of RF energy to assess the early postRF appearance of the mucosa. Typically, collagen contraction is seen immediately after RF delivery, with tightening of the GEJ (6-8). The escharification of the collagen caused by the RF energy delivery results in tightening of the GEJ, increased gastric yield pressure and LES pressure, and decreased frequency of transient lower esophageal relaxations.

The results of a controlled, one-year, short term trial are not yet available, but an open-label American trial of RF energy delivery using the Stretta procedure has been reported in 118 middle-aged GERD patients previously treated for a mean of 9.5 years with a median drug requirement of omeprazole $40 \mathrm{mg} /$ day $(6,8)$. Subjects had daily heartburn and/or regurgitation requiring daily medication. Their mean LES pressure was greater than $5 \mathrm{mmHg}$, and they had normal LES relaxation, esophageal body amplitude greater than $30 \mathrm{mmHg}$, and a minimum esophageal acid exposure time greater than $4 \%$ over $24 \mathrm{~h}$. Excluded were patients with a hiatal hernia longer than $2 \mathrm{~cm}$, severe esophagitis, severe dysphagia, previous esophageal or gastric surgery, severe heart disease (American Society of Anesthesiologist class III or IV), a history of collagen vascular disease or pregnancy. The mean procedure time was $53 \mathrm{~min}$, and the complication rate was $8.6 \%$. The most frequent adverse effects were superficial mucosal injury (2.5\%), and fever or chest discomfort (each 1.7\%). GERD symptom and satisfaction scores, and the quality of life score improved over 12 months, with $60 \%$ of patients not using any medication for GERD at 12 months.

The postmarketing experience with Stretta in the United States has revealed that the total complication rate of 1200 procedures is only $0.83 \%$. Patient selection and attention to the technical details are important, and longer term and cost effectiveness studies will help to establish the exact role of this endotherapy in the care of patients with GERD, including those with nonerosive reflux disease.

\section{ENDOSCOPIC INJECTION OF A BIOPOLYMER}

Enteryx (ethylene-vinyl-alcohol) is a biocompatible, nonbiodegradable polymer that is injected directly into the muscle of the gastric cardia. In a pilot study of 15 patients with GERD, Enteryx (usual dose, four injections) was placed into the cardia to produce a circular diffusion of the polymer. This resulted in an increase in the LES pressure one month later, with four patients $(27 \%)$ needing to go back on PPI (9). The outcome of a larger, longer term multicentre study is awaited.

\section{ENDOSCOPIC FULL-THICKNESS PLICATION}

The endoscopic full-thickness plication system (NDO Surgical, Inc, USA) is designed to fixate the stomach tissue 
near the GEJ, with serosa-to-serosa apposition (10). The serosa-to-serosa tissue union that is created appears to accentuate and restore the valvular mechanism of the GEJ. The device consists of a reusable instrument and a singleuse suture-based implant. A small human feasibility study was performed in six patients with GERD who underwent endoscopy with conscious sedation, at which time plications were performed in the stomach within $2 \mathrm{~cm}$ of the GEJ. Three months after plication, the quality of life symptom score questionnaire demonstrated a $43 \%$ improvement in the average heartburn score and a 58\% improvement in the average regurgitation score $(2,10)$. The quality of life of these patients also improved, with the GERD HealthRelated Quality of Life questionnaire demonstrating an average improvement in heartburn after meals of $63 \%$, while heartburn standing up and heartburn lying down improved by $82 \%$ and $88 \%$, respectively. Ambulatory $24 \mathrm{~h}$ $\mathrm{pH}$ monitoring performed three months after plication demonstrated an improvement in the total time that the intraesophageal $\mathrm{pH}$ was less than 4 , as well as a decrease in the total number of reflux episodes. This is a promising endoscopic approach, but more data are needed to ascertain the exact clinical role of full-thickness endoscopically placed plication.

These four new endotherapies for GERD are designed to strengthen the LES pressure, and to thereby reduce acid regurgitation with the resultant acid-induced symptoms and damage, and thereby to improve the quality of the patient's life. To better understand the role of the LES and the GEJ in reflux disease, and the pathophysiological basis for reflux disease, the accompanying paper by DeMeester (pages 332 336) provides a state-of-the-art consideration of the importance of this barrier.

\section{REFERENCES}

1. Bell NJV, Hunt RH. Role of gastric acid suppression in the treatment of gastro-oesophageal reflux disease. Gut 1992;33:118-24.

2. Chuttani R. Transural suture: endoscopic full-thickness plication system for GERD. Fourteenth International Course on Therapeutic Endoscopy. Toronto, October 10-13, 2001.

3. Swain P. Endocinch. Fourteenth International Course on Therapeutic Endoscopy, Toronto, October 10-13, 2001.

4. Kadirkamanathan SS, Evans DF, Gong F, Yazaki E, Scott M, Swain CP. Antireflux operations at flexible endoscopy using endoluminal stitching techniques: an experimental study. Gastrointest Endosc 1996;44:133-43.

5. Filipi CJ, Edmundowicz SA, Gostout CJ, et al. Transoral endoscopic suturing for treatment of GERD: a multicentre trial. Gastrointest Endosc 2001;53:541-5.

6. Triadafilopoulos G, Dibaise JK, Nostrant TT, et al. Radiofrequency energy delivery to the gastroesophageal junction for the treatment of GERD. Gastrointest Endosc 2001;53:541-5.

7. Utley DS, Kim M, Vierra MA, Triadafilopoulos G. Augmentation of lower esophageal sphincter pressure and gastric yield pressure after radiofrequency energy delivery to the gastroesophageal junction: a porcine model. Gastrointest Endosc 2000;52:81-6.

8. Triadafilopoulos G. Novel therapies for reflux: Stretta ${ }^{\circledR}$ procedure. Fourteenth International Course on Therapeutic Endoscopy. Toronto, October 10-13, 2001.

9. Deviere J, Silverman D, Pastorelli A, et al. Endoscopic implantation of a biopolymer in the lower oesophageal sphincter for gastroesophageal reflux: a pilot study. Gastrointest Endosc 2001;53:AB74. (Abst)

10. Chuttani R, Sud R, Sachdev G, et al. A novel endoscopic full thickness plicator for the treatment of GERD: Early clinical results in human subjects. 9th United European Gastroenterology Week. Amsterdam, October 6-10, 2001. 


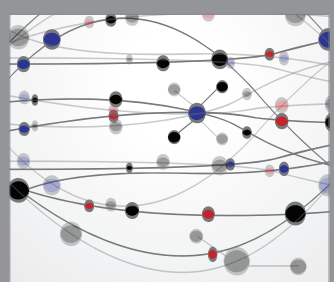

The Scientific World Journal
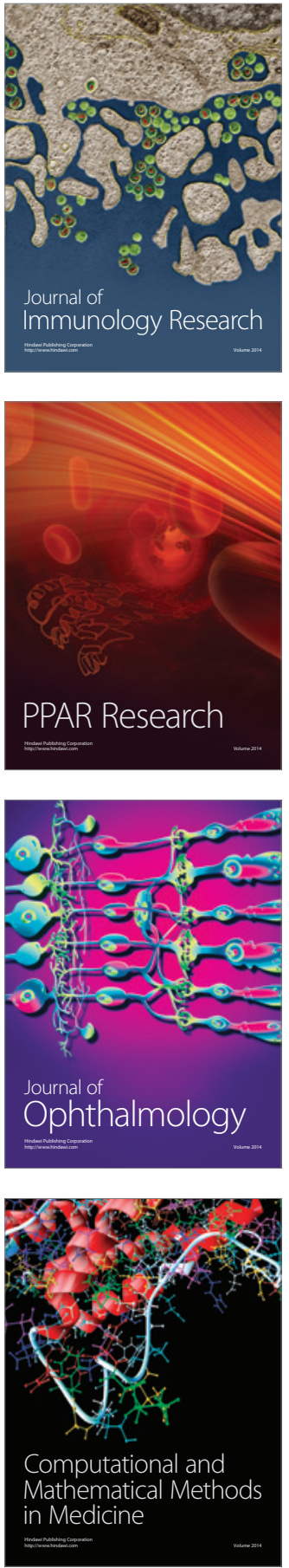

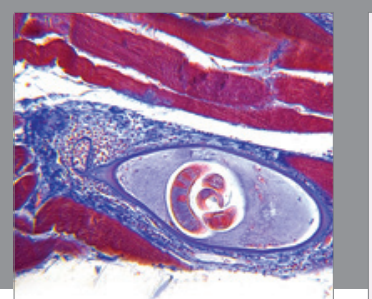

Gastroenterology Research and Practice

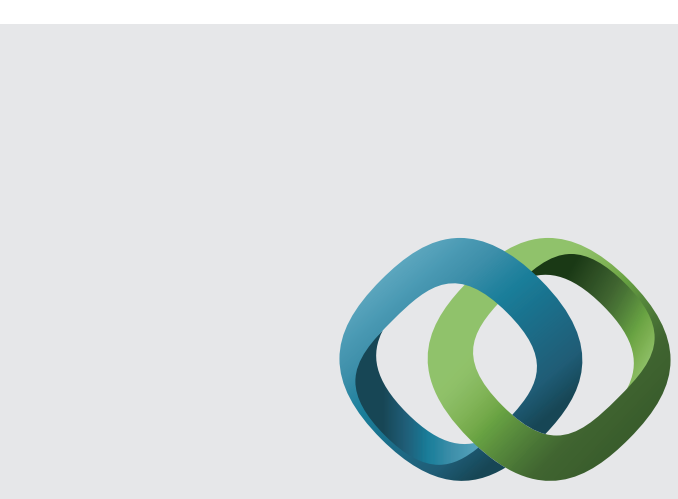

\section{Hindawi}

Submit your manuscripts at

http://www.hindawi.com
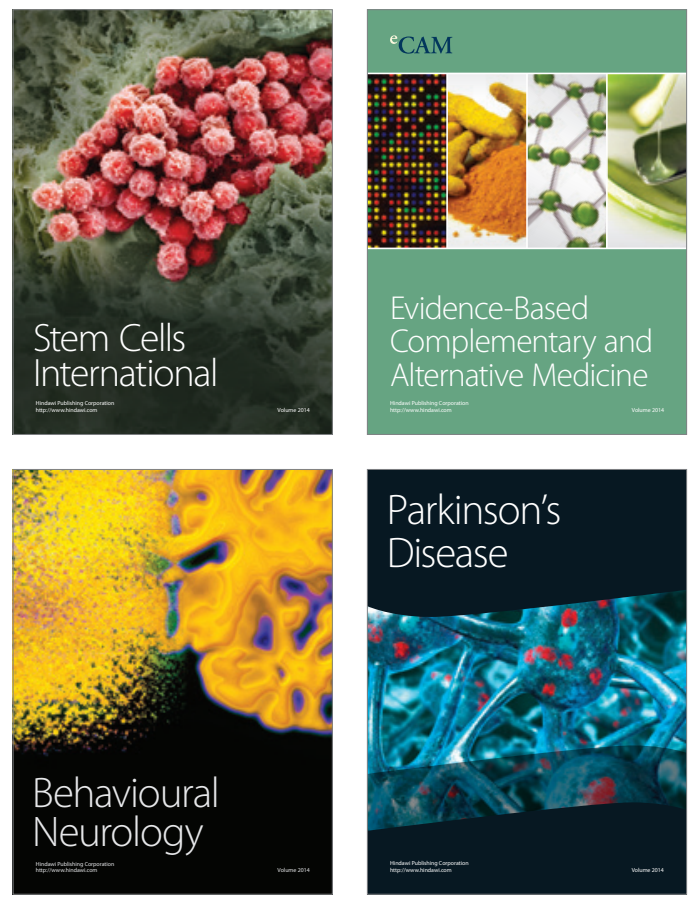
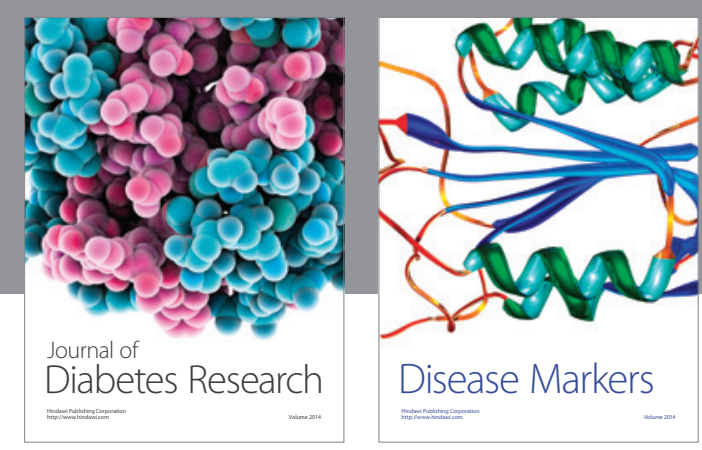

Disease Markers
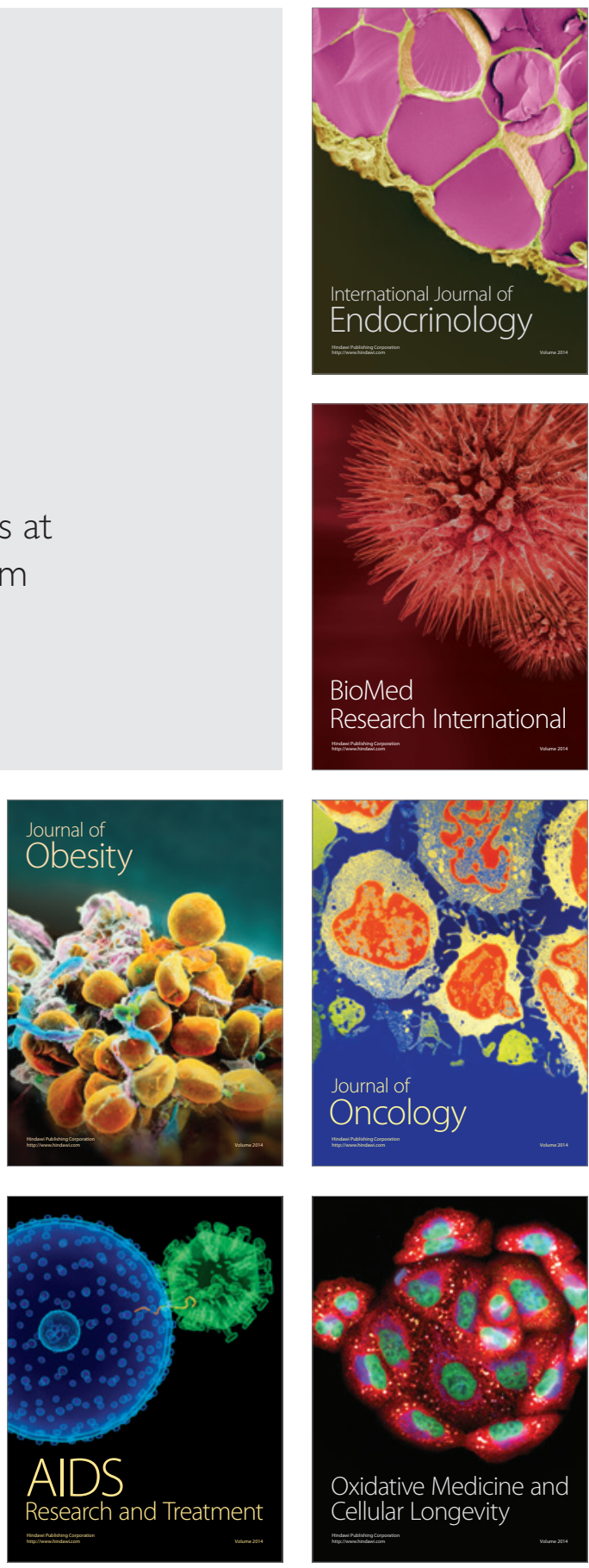